\title{
1 Abstract
}

2 The purpose of this study was to assess the effect of a tailored cognitive-behavioral

3 therapy (CBT) for depression and anxiety symptoms in Mexican terminal cancer

4 patients. A non-concurrent multiple baseline design across individuals was used. Nine

5 patients participated in the study, and they received four to six therapy sessions. The

6 effect size of the intervention range (NAP and Tau indexes) in the nine patients

7 indicated that the intervention had from weak to moderate impact for anxiety and

8 depression symptoms in this population. Similarly, the overall standardized mean

9 difference was also moderate, with a reduction of 0.54 and 0.76 standard deviations in

10 depression and anxiety symptoms, respectively. This study provides initial evidence

11 supporting the positive effect of CBT for patients with terminal cancer and with mood

12 problems when facing their impending death.

13 Keywords: Terminal Cancer, depression, anxiety, cognitive behavioral therapy, single-

14 case experimental design

\section{Introduction}

16 Depression and anxiety are the most frequently reported emotional problems by

17 advanced cancer patients. Studies show that $10 \%$ to $48 \%$ of these patients are anxious

18 (Mitchell et al., 2011; Spencer, Nilsson, Wright, Pirl, \& Prigerson, 2010), and 9\% to

$1940 \%$ are depressed (Hotopf, Chidgey, Addington-Hallm, \& Ly, 2002; Teunissen et al.,

20 2007). Patients with anxiety, depression, or a combination of both, tend to report greater

21 frequency and intensity of physical symptoms compared to patients who do not display

22 these emotional problems (Delgado-Guay, Parsons, Li, Palmer, \& Bruera, 2009).

23 Treatments such as antidepressants, anxiolytics, benzodiazepines, in

24 combination with psychotherapy are usually considered first-line interventions for

25 anxiety and depression. Current evidence-based information suggests that cognitive 
behavioral therapy (CBT) should be considered to treat anxiety and depression in advanced cancer patients (Okuyama, Akechi, Mackenzie, \& Furukawa, 2017; Rayner, Price, Hotopf, \& Higginson, 2011; Traeger, Greer, Fernandez-Robles, Temel, \& Pirl, 2012).

Given the cognitive and physical decline in terminal cancer patients, it is noteworthy that research in this field had to adapt components of CBT to the needs and characteristics of these patients. The number of sessions with this population tends to be shorter (4 to 8 sessions) than the number of sessions in other settings (Anderson, Watson, \& Davidson, 2008; Savard et al., 2006). Investigators have also tailored certain components of CBT to address realistic but intrusive and distressing thoughts about symptoms, functionality, and death (Greer et al., 2012; Greer, Park, Prigerson, \& Safren, 2010). In addition to traditional face-to-face therapy, researchers have assessed other modalities of intervention delivery, such as group therapy (Edelman, Bell, \& Kidman, 1999) and home-based therapy (Moorey et al., 2009) with positive effects in depression and anxiety symptoms respectively.

Despite efforts to adapt CBT to terminal cancer patients, the special conditions of patients living in developing countries such as Mexico differ from patients who have participated in CBT and terminal cancer studies elsewhere. Such differences may affect the ecological validity and cultural sensitivity of those interventions for Hispanic populations (Bernal, Bonilla, \& Bellido, 1995; Okuyama et al., 2017). Late referral to palliative care services is very common in developing countries, and it leads to 1) short life expectancy in palliative care patients (an average of three months); and 2) more physical symptoms experienced by terminally ill patients. Additionally, salient factors specific to Mexican or Hispanic populations ought to be considered when designing or adapting a therapy: 1) at least 55.3 million Mexicans live in poverty or extreme poverty, 
51 so they lack the necessary income to satisfy basic health and transportation needs; and

52 2) in Mexico it is common that not only nuclear family members, but also extended

53 family, actively participate in a patient's care and decision-making (Consejo Nacional

54 de Evaluación de la Política de Desarrollo Social, [National Council for the Evaluation

55 of Social Development Policy], 2015; Covarrubias-Gómez, Hernández-Martínez, Ruiz-

56 Ramírez, \& López Collada-Estrada, 2014; De Vos, Solís, \& Montes de Oca, 2004).

57 The difficult conditions that Mexican terminal cancer patients encounter and the

58 lack of empirical evidence make it necessary to assess CBT strategies that are specific

59 to this population. Therefore, it is pertinent to develop cultural adaptations of CBT

60 relevant to the conditions of this population. For example, interventions would ideally

61 include a fewer number of sessions, emphasize psychological strategies for symptom

62 control, use home-based therapy to avoid patients' fatigue due to transportation or lack

63 of financial resources, and allow flexibility to involve one or more family members.

64 In addition to the clinical adaptations, Penrod \& Morrison (2004) have

65 highlighted the need to increase research in this area with particular attention to the

66 "challenges for palliative care research." Conducting research in patients with

67 advanced cancer who are close to death involves numerous ethical, clinical and

68 methodological challenges. Researchers in this field should be focused on application of

69 methodology that is adapted to the patient's context and needs. Although randomized

70 controlled trials (RCT) are the "gold standard" for conducting clinical research in the

71 current evidence-based practice, when RCT are applied in palliative care settings

72 several limitations have been documented such as unethical issues for withholding the

73 treatment from the control group; the lack of feasibility to employ RCT for every

74 palliative care clinical question and patient population; poor patient accrual for the

75 studies; and the aim of RCT to demonstrate efficacy but not necessarily effectiveness. 
76 Studies are therefore needed to implement novel and realistic systems for interventions

77 targeting people with advanced cancer, given the difficulty of conducting clinical trials

78 in this population (Okuyama et al., 2017).

The use of single-case experimental design (SCED) or N-of-1 trials as they are

80 formally known in medicine (Tate et al., 2016) could be an alternative approach to

81 advance in the research of available interventions within the field for patients with

82 terminally ill cancer in palliative care settings. Recently, the importance of conducting

83 this kind of research has been highlighted, because SCEDs (a) allow rigorous internally

84 valid scientific investigation of the effectiveness of a particular treatment for an

85 individual (Lobo, Moeyaert, Cunha, \& Babik, 2017), rather than the population mean

86 (Normand, 2016); (b) help to assess early effects (Graham, Karmarkar, \& Ottenbacher,

87 2012); (c) are less expensive and more feasible than other experimental approaches; (d)

88 can complement information retrieved from other experimental designs (Shadish,

89 Hedges, Horner, \& Odom, 2015); (e) favor the extrapolation of results on the basis of

90 the comparison between the features of the client, behavior, and setting for which

91 effectiveness has been demonstrated and the features of the situation any given

92 practitioner is facing (Schlosser, 2009); and (f) when several studies are available on the

93 same intervention for the same type of problem the results may be pooled via meta-

94 analyses (Jenson, Clark, Kircher, \& Kristjansson, 2007; Punja et al., 2016).

Given the above, using the SCED can be an appropriate option to conduct

96 psychological research with advanced cancer patients (Lévesque, Savard, Simard,

97 Gauthier, \& Ivers, 2004). Even though an adapted CBT seems to be a promising

98 approach for those with considerable morbidity, no empirical data exist to discern

99 whether this mode of therapy is effective in Mexican terminal cancer patients. 
100 Therefore, the aim of this study was to assess the effect of a tailored CBT for depression

101 and anxiety symptoms in Mexican terminal cancer patients. A secondary aim was to

102 evaluate the effect of the intervention on the leisure activities self-report and on the type

103 of thoughts related to the patient's advanced cancer, as well as to their perception of the

104 main benefits and harm they experienced throughout the therapy.

\section{Method}

106 Design

107

A non-concurrent A-B multiple baseline design across individuals was used.

108 Multiple-baseline design is highly recommended because "the effects are demonstrated

109 by introducing the intervention to different baselines at different points in time. If each

110 baseline changes when the intervention is introduced, the effects can be attributed to the

111 intervention rather than to extraneous events" (Kazdin, 2011, p. 144). Given the short

112 life expectancy of participants, it was decided to use three cohorts of three patients in

113 each cohort in order to avoid prolonged baseline records that could lead to a patient's

114 death without treatment and also in order to generate at least three replications of the

115 treatment intervention. Phase "A" consisted of the baseline, which included an

116 evaluation using the Hospital Anxiety and Depression Scale (HADS). The duration of

117 the baselines was two, three or four assessments during this phase. For each cohort,

118 each of the previously specified baseline lengths occurred once. Simple computerized

119 randomization was used to determine the time at which phase change occurs for each

120 participant. During this phase, patients and primary caregivers were trained to fill out

121 their activities, thoughts and mood diary daily, and their HADS instruments weekly.

122 Phase "B" consisted of intervention and post-assessment. During this phase,

123 patients completed their activities, thoughts and mood diary and anxiety and depression 
124 mood records; they also completed the HADS weekly until their health permitted, or for

125 up to one month after completing the treatment.

\section{Participants}

127 The following inclusion criteria were required for study participation: patients at

128 least 18 years of age; diagnosis of terminal cancer (stage IV cancer with no curative

129 treatment and referred to palliative care); and clinically significant anxiety and/or

130 depression symptoms according to the HADS scores (depression $\geq 7$; anxiety $\geq 8$ ). Three

131 participants had depression symptoms only, and six had depression and anxiety

132 symptoms. The exclusion criteria included: patients with stage I, II, and III cancer;

133 patients with cognitive impairment or delirium; and patients with low functionality

134 levels which prevented them from taking therapy (functionality was measured using the

135 Palliative Performance Scale [PPS] $\leq 30 \%$; see the instruments description). 117

136 patients with terminal cancer were assessed during the fourteen months that this

137 investigation lasted, but 108 patients (92\%) were not in adequate conditions to

138 participate in this research (90 were extremely ill to participate [PPS $\leq 30$ ]; 4 developed

139 delirium; 5 had subthreshold of anxiety or depression; and 9 had other reasons). Nine

140 terminal cancer patients from the Pain and Palliative Care Department of a General

141 Hospital in Mexico City participated in this study. Six women and three men were

142 included, with an average age of 63.3 years (range: $40-83$ years). The average score for

143 the Palliative Performance Scale (PPS, see description below) was 64 (range: 40-90);

144 and the mean survival was 119 days. Pancreatic, liver and cervical terminal cancers

145 were common in these participants. Additional demographics are displayed in Table 1. 
CBT was delivered at patients' homes (living room or patient's bedroom), which

150 were located in Mexico City's metropolitan area. The shortest travel time by taxi from

151 the hospital to a patient's home and back was 25 minutes, and the longest was 160

152 minutes. All patients signed an informed consent form before participating in the study.

153 Permission for the research was granted by the "Hospital General Dr. Manuel Gea

154 González" in Mexico City with registration number 47-01-2014.

\section{Instruments}

$156 \quad$ Clinical medical records of patients were used to verify health and

157 sociodemographic information, as well as to obtain data on their functional status and

158 physical symptoms. An exhaustive review was performed in order to find studies

159 reporting validity, reliability, specificity and sensitivity of instruments to assess anxiety

160 and depression in oncologic and terminal patients (Mitchell, Meader \& Symonds, 2010;

161 Vodermaier, Linden, \& Siu, 2009). Until now there is no a single method specifically

162 designed to accomplish those purposes, so it is recommended to use a two-item

163 interview (initial assessment), combined with self-reported assessment and

164 behavioral/thoughts records. All of them are described below.

\section{Instruments used for screening purposes}

166 Two-question interview. Two questions derived from the Edmonton Symptom

167 Assessment System (ESAS) were used as an initial screening of severity for anxiety and

168 depression (“Are you anxious?” “Are you depressed?”). We scored ESAS items through

169 a numeric scale ranging from 0 (absence of the symptom) to 10 (worst possible severity;

170 Hannon et al., 2015). If patients reported anxiety or depression (ESAS > 1), HADS

171 scales were applied. This assessment method has proven to be valid and reliable for the

172 Spanish-speaking population $(\alpha=0.75-0.86)$, and it has further shown to be a useful 
173 tool to assess the symptoms of the palliative population in Mexico (Carvajal, Hribernik,

174 Duarte, Sanz-Rubiales, \& Centeno, 2013; Covarrubias-Gómez et al., 2014).

175 Palliative Performance Scale (PPS). This scale is used to evaluate the

176 palliative patient's functionality level. Palliative care physicians completed the PPS

177 scale to identify the patient's level of functionality in five domains: ambulation,

178 activity, and evidence of disease; self-care and intake; and level of consciousness. For

179 each domain, the physician establishes the value that best represents the patient's ability

180 and health. This value ranges between $100 \%$ (patient with no evidence of disease) and

$1810 \%$ (patient who has died). If patients showed a PPS lower than $30 \%$, they were not

182 included in the study because their PPS score reflected fewer survival days (Lau et al.,

183 2009). The PPS scale has shown to be valid and reliable for the Spanish-speaking

184 population (test-retest reliability was 0.89 ) and has proven to be a useful tool to assess

185 the functionality of the palliative population in Mexico (Barallat et al., 2017;

186 Covarrubias-Gómez et al., 2014).

Confusion and delirium assessment. Two self-reported scales adapted and

validated for Spanish-speaking populations were employed to identify cognitive disorders associated with chronic diseases (Lobo et al., 1999) and delirium (Wei,

190 Fearing, Sternberg, \& Inouye, 2008). If patients had cognitive problems or delirium,

191 they were not included in the study.

192 Instruments used to measure the study variables

193 Hospital Anxiety and Depression Scale (HADS). HADS is a widely-used

194 scale to measure anxious or depressed mood in medical patients, including those

195 diagnosed with cancer (Zigmond \& Snaith, 1983). The scale includes 14 Likert-type

196 questions (seven of the items relate to anxiety and seven relate to depression) with 4

197 response options, ranging from 0 to 3, with higher scores indicating worse symptoms. A 
198 high sensitivity (82\%), specificity (77\%) and clinical utility index (.74) were reported

199 for the HADS (Mitchell et al., 2010). This study used a HADS version adapted to the

200 Mexican population with a good Cronbach's alpha $(\alpha=.86)$ resulting in a depression

201 cut-off point of 7 and an anxiety cut-off point of 8 (López- Alvarenga et al., 2002).

\section{Self-reported clinical outcomes}

Activities, thoughts and mood diary. Patients and caregivers were asked to

204 complete one diary in which they recorded the frequency of leisure activities, their

205 thoughts related to depression, anxiety, and cancer, and the patient's mood. According

206 to clinical experience and previous research (Greer et al., 2010), leisure activities were

207 defined as a patient's effort to engage in self-perceived pleasant activities consistent

208 with their declining health condition (frequency of leisure or home support activities

209 were fulfilled; see Table 3) Similarly, they were asked to write and describe negative

210 thoughts that could be associated with depression and anxiety. Finally, patients recorded

211 their moods on a daily basis and the most significant events, both positive and negative,

212 occurring in their everyday lives. Similar records have been used in patients with

213 advanced cancer (Lévesque et al., 2004).

214 Finally, relatives and patients were asked five open-ended questions once the

215 treatment was completed: From your perspective 1) What effects did the therapy have

216 on the depression/anxiety of the patient? 2) What were the most useful components you

217 observed in the therapy? 3) What were the most complicated components you observed

218 in the therapy? 4) Did the therapy cause any harm to the patient? And 5) What do you

219 think about the fact that this therapy was provided at your home? Similar interviews

220 have been used in patients with advanced cancer (Lévesque et al., 2004).

\section{Intervention}


Regarding the treatment, a cultural adaptation of CBT was conducted according

223 to the Mexican context. Further descriptive information is provided in Table 2. Study staff convened meetings to standardize the intervention components and safeguard the integrity of the treatment. Previous terminal cancer studies were reviewed to identify the main components used in CBT for patients with depression and anxiety in general, and for those with advanced cancer in particular (Greer, Graham, \& Safren, 2009; Greer et al., 2010). Based on this review, an intervention manual was developed detailing the techniques used for each component of the therapy. Further descriptive information is provided in Table 3. The modules were: 1) psycho-education on CBT principles (Norcross, 2011; Padesky \& Mooney, 1990); 2) relaxation training (Greer et al., 2010; Stetter \& Kupper, 2002); 3) identification and modification of negative thoughts related to anxiety and depression (Greer et al., 2010; 2012); and 4) planning leisure activities as well as strategies for physical symptoms (Greer et al., 2010). Following the review conducted and considering that terminal cancer patients' physical condition worsens with time, it was decided that the intervention would be provided in a range of four to six sessions within a period of three weeks. Thus, the physical deterioration or death of the patient could be anticipated. On average, the intervention was delivered in 4.6 sessions (range 4-6 sessions) over the course of 19 days (range of 11-26 days: 2.8 weeks). In eight out of nine patients, their relatives (wives, sisters, daughters, and

241 nieces) also attended the therapy; hence, primary caregivers were always present for 242 most sessions. Therapy was provided twice a week.

Treatment was delivered by the first author of this paper (he was a clinical

244 psychology graduate student at the time this study was conducted). Four other licensed psychologists individually joined the therapy sessions with the sole purpose of acting as independent assessors for the baseline-assessment and post-assessment, rating anxiety 
247 and depression symptoms using the HADS, as well as completing a checklist on the

248 session's integrity. Three assessors took part in all sessions with two patients, and one

249 assessor took part in all sessions with three patients.

250 Six participants completed the CBT modules in the order outlined in the

251 treatment manual; however, three patients were very anxious at the beginning of the

252 therapy, which led to the clinical decision to start the intervention with the relaxation

253 training. Finally, according to the treatment integrity checklist, the nine patients

254 received all components included in the treatment manual.

[TABLE 2]

\section{[TABLE 3]}

Patients completed at home and with assessors' help the post-assessment scales one week after completing the intervention. They also had weekly follow-up assessments for approximately one month during which they continued to add entries to their diaries and completed the HADS. In four cases, patients failed to complete the one-month follow-up because they died.

\section{Data Analysis}

Visual and statistical analyses. Visual analysis was conducted according to the suggestions of Kratochwill et al. (2010): six features were used to examine within- and between- phase data patterns: 1) level, as represented by an average, 2) trend, 3) variability, 4) immediacy of the effect: comparing the last three baseline phase measurements to the first three intervention phase measurements, 5) overlap and 6) consistency of data patterns across similar phases. The visual analysis was aided by the website described in Manolov (2018). Regarding the statistical analysis, no gold standard exists, because the different alternatives focus on different data features, and 
271 all of them have advantages and flaws (Tate et al., 2013). We decided to use both nonoverlap indices (Non-overlap of All Pairs index, NAP; Parker \& Vannest, 2009 and

273 Tau-U; Parker, Vannest, Davis, \& Sauber, 2011) and the between-cases standardized

274 mean difference (BC-SMD; Hedges, Pustejovsky, \& Shadish, 2013). BC-SMD was used to obtain an overall quantification of the difference between

276 baseline and intervention phase scores of anxiety and depression, both in raw and in 277 standardized terms. BC-SMD was obtained using the $s c d h l m$ package for R

278 (Pustejovsky, 2016a) and the website (Pustejovsky, 2016b). We performed two

279 different statistical analysis because: (a) the approaches focus on different aspects of the 280 data; (b) the nonoverlap indices offer a quantification for each participant separately,

281 whereas the BC-SMD offers an overall quantification; and (c) the results of several 282 effect size measures can be compared in order to assess the consistency of the results 283 (Kratochwill et al., 2010). The results of the visual and statistical analyses can be 284 replicated by using the raw data (available in Excel format at https://osf.io/q7uhe/) and 285 by executing the analyses via the websites mentioned above.

286 The BC-SMD represents the data in each phase using the phase means, that is, 287 as flat trend lines. In contrast, NAP and Tau-U do not model or reduce to data to a mean 288 or a trend line. NAP and Tau-U rather quantify the proportion of data points in the 289 intervention condition that are improve relative to baseline phase measurements 290 (Ledford, Lane, \& Severini, 2018). NAP is closely related to the Mann-Whitney U test 291 (Parker \& Vannest, 2009) and it can also be interpreted as a probability of superiority

292 (Grissom, 1994): the probability that a randomly selected intervention data point would represent an improvement over a randomly selected baseline data point. Thus, NAP and

294 Tau-U represent ordinal measures (i.e., how many data points are improved after the 295 intervention), in comparison to the BC-SMD that measures the distance between the 
296 measurements from different conditions (i.e., how large is the improvement). Finally,

297 the difference between NAP and Tau-U is that the latter allows accounting for

298 improving baseline trend. NAP and Tau-U were computed using a specific website

299 (Vannest, Parker, Gonen, \& Adiguzel, 2016).

$300 \quad$ Reliable Change Index/Clinically Significant Change. The Reliable Change

301 Index/Clinically Significant Change (RCI/CSC) method was used to determine if

302 participants underwent considerable enough changes during their treatment, so that such

303 changes could be regarded clinically significant (Morley, \& Dowzer, 2014). RCI/CSC

304 analysis was conducted by considering the nine patients separately for both anxiety and

305 depression scores. The first score from baseline was deemed the pre-treatment score,

306 and the last reported score was deemed the post-treatment score. Reliability for this

307 measure was obtained from mean values reported in a literature review of HADS

308 validity data (Bjelland, Dahl, Haug, \& Neckelmann, 2002). Means and standard

309 deviation of clinical norms were obtained from a sample of palliative care patients being

310 treated at home (Austin, Wiley, McEvoy, \& Archer, 2011) and comparison norms were

311 obtained from the general population normative data (Hinz et al., 2014). According to

312 Jacobson (1991), statistical criteria for defining Clinically Significant Change (CSC)

313 was that the level of functioning after therapy should fall outside the range of the

314 clinical population, in the direction of the reference group.

315 Further assessment of self-reported clinical outcomes

316 The non-parametric Wilcoxon signed-rank test was used to determine

317 differences in distributions of pooled data of behavioral activation during pre- and post-

318 treatment. A significance level of $p \leq .05$ was used to label differences as statistically

319 significant. Finally, the main disease-related negative thoughts are mentioned, as well as

320 the major clinical effects on the patient's functioning which were significant for patients 
321 in our intervention. This assessment aligns well with the call to consider more carefully

322 the social validity (Snodgrass, Chung, Meadan, \& Halle, 2018).

323 Results

\section{Depression}

325 Figure 1 shows the data for depression symptoms as outcome for the nine

326 subjects in the three cohorts.

327 The visual data analysis shows that nine patients reported elevated depression

328 symptoms at baseline. The baseline data were relatively stable for all patients, except

329 for the improving trend for patient 2 from cohort 3 and the deteriorating trend for

330 patient 3 from cohort 3 . For patient 2 from cohort 1 , and patient 1 from cohort 2 we

331 also decided to control for improving baseline trend using Tau-U instead of NAP,

332 although the trend was less clear. During phase B, all nine patients showed a small

333 overall decrease in level in their depression scores; this decrease was immediate for

334 most patients. For two of the participants (patient 1 from cohort 2 and patient 1 from

335 cohort 3) the scores were systematically in the normative range, whereas patient 3 from

336 cohort 3 also achieved this result at the end of the intervention. There is certain

337 (although far less than perfect) consistency of the decrease in depression across 338 participants.

\section{[FIGURE 1]}

340 Due to few clear trends observed in the data, we considered that the application

341 of the BC-SMD, which assumes lack of trend, was reasonable. The overall average

342 difference between baseline and intervention was -3.16 HADS score points,

343 representing a standardized mean difference of -0.76 (with a confidence interval

344 ranging from -1.33 to -0.21 ). Given that $\mathrm{BC}-\mathrm{SMD}$ was created to be equivalent to 
345 Cohen's $d$ (Hedges et al., 2013), such a difference is very close to a large effect $(0.80)$, 346 as per Cohen's (1992) benchmarks.

347 The values of the nonoverlap indices for each individual are presented in Table

348 4. There is a decrease for all participants, except for one. The NAP values indicate a 349 moderate effect (between 0.66 and 0.92, as per Parker and Vannest, 2009), whereas the

350 two (out of three) Tau-U negative values would represent a large change (between 0.60 351 and 0.80, according to Vannest \& Ninci, 2015).

[TABLE 4]

An overall assessment of the scores in depression reveals that all intervention

354 phase averages are below the baseline averages and that for two individuals these

355 intervention averages are in the normative range.

Anxiety

Figure 1 shows the data for anxiety symptoms as outcome for the nine subjects

359 in the three cohorts.

360 The visual data analysis shows that only six subjects experienced elevated anxiety at 361 baseline. Patient 3 from cohort 1 shows a clear improving baseline trend. For patient 1

362 from cohort 2 and patients 2 and 3 from cohort 3 there could also be an improving

363 trend, but it is not that visually clear. In order to be conservative, we still controlled for

364 such trends by using Tau-U instead of NAP for these four participants. For most

365 participants there was an immediate change in level. In contrast, an improving trend and

366 a somewhat delayed change was observed during the intervention phase for two

367 participants: for patient 3 from cohort 2 and, to a lesser extent, for patient 1 from cohort

3683 . Among the participants whose anxiety scores were not in the normative range already 369 during the baseline phase, one participant (patient 1 from cohort 3) achieved normative 
370 scores for most of the intervention phase measurements. Additionally, further four

371 participants (patient 2 from cohort 1, patient 3 from cohort 2, and patients 2 and 3 from

372 cohort 3) achieved normative anxiety scores for some intervention phase measurements.

373 The consistency of the decrease in anxiety across participants is rather low.

374 Due to few clear trends observed in the data, we again considered that the

375 application of the BC-SMD, which assumes lack of trend, was reasonable. The overall

376 average difference between baseline and intervention was -2.82 HADS score points,

377 representing a standardized mean difference of -0.54 (with a confidence interval

378 ranging from -0.94 to -0.17 ). Given that $\mathrm{BC}-\mathrm{SMD}$ was created to be equivalent to

379 Cohen's $d$ (Hedges et al., 2013), such a difference is very close to a moderate effect

380 (0.50), as per Cohen's (1992) benchmarks.

381 The values of the nonoverlap indices for each individual are presented in Table

382 5. There was a decrease for all participants, except for one. The NAP values indicate a

383 moderate effect (between 0.66 and 0.92, as per Parker and Vannest, 2009) for four of

384 the five participants. Regarding the three (out of four) negative (i.e., improving) Tau-U

385 values: one represents a small change (between 0 and 0.20 ), one represents a moderate

386 change (between 0.20 and 0.60), and one represents a large change (between 0.60 and

387 0.80, according to Vannest \& Ninci, 2015).

388 Overall, for the anxiety scores, the intervention phase averages are below the

389 baseline averages for seven of the nine individuals. For five individuals the intervention

390 averages are in the normative range, but for four of them they were already normative in 391 the baseline.

392 Adverse Events

393 Given the extremely ill state of health of the patients, three patients died during

394 phase B (patients 2 and 3 from cohort 1; patient 2 from cohort 2), and one patient 
395 developed delirium (patient one/cohort one). Patient 2 from cohort 3 experienced a

396 number of problematic stressors during therapy (his mother died, he got a car stolen and

397 his brother disappeared).

398 Reliable Change Index/Clinically Significant Change

It was found that 2 out of 9 patients $(22.22 \%)$ had both a reliable and a clinically

400 significant change for depressive symptoms. Both patients had levels of depressive

401 symptomatology before the intervention well above the cut point posed by the instrument (scores of 12 and 10) and reached levels just at the cut-off point (>7) and well below it (1). Seven patients made no change but did not deteriorate with respect to their symptoms of depression. Similarly, 3 out of 9 patients $(33.33 \%)$ had both a reliable and a clinically significant change in their anxiety symptoms. These patients had from moderate to very high levels of anxious symptoms prior to the intervention (scores of 14, 14 and 17) and all of them decreased their levels below the cut-off point for anxiety $(>8)$.

\section{Self-reported clinical outcomes}

\section{Leisure Activities and Negative Thoughts}

For behavioral activation, the Wilcoxon signed-rank test was applied to compare

412 the value during pre- (12.5) and post-assessment (15.5). The result showed a statistically

413 significant increase $(Z=2.668, p=.008)$. Thus, CBT encouraged patients to increase

414 their leisure behaviors or to carry out other activities. It is important to mention that

415 many problems were faced in getting patients or their caregivers to complete their

416 behavior records, because they would do so intermittently or in a non-descriptive

417 manner. The psychology staff tried to complete behavioral records retrospectively with

418 patients whenever possible (retrospective records, 21\%). Because records were not

419 available for every session, the average of weekly behaviors and thoughts of patients 
were calculated (behavioral records missing, 34.5\%) negative thoughts (missing thought

421 records, 36.2\%; retrospective records, 16.5\%). Similarly, the leisure activities record did not follow a behavior coding protocol as recommended in recent studies by Busch,

Uebelacker, Kalibatseva \& Miller (2010). We will return to this point in the limitations section. In most cases, negative thoughts were not irrational but real and distressing; therefore, therapists encouraged patients to change their thoughts for more adaptive and comforting ones. Identified thoughts were classified according to frequency of occurrence as follows: a) disease progression and physical symptoms, b) functionality and daily activities, c) concerns related to loved ones, and d) social and financial problems. These categories were created using the most frequent thoughts recorded in patients' mood diaries and thoughts reported verbally during therapy.

All nine patients considered that CBT had positive effects which helped them to control or reduce their mood, and none of them felt that the therapy caused them any harm. Most patients $(n=8 / 9)$ mentioned that autogenic relaxation and guided imagery

434 produced immediate tranquilizing effects. Additionally, these components helped

435 patients to find relief from negative physical symptoms such as pain or nausea, and they

436 deemed them easy to perform. For patients with limited capacity to go out, guided

437 imagery allowed them "to go" to places they liked (e.g., their hometowns, a beach, a 438 place in the forest) and to experience a pleasant feeling at that particular moment. The 439 intervention component that focused on changing negative thoughts was the most 440 challenging for patients. Those with a higher level of education found it easier to 441 understand the relationship between thoughts, feelings, behaviors, and physical 442 symptoms. Yet, for the remaining patients (6 out of 9), thought change required the 443 greatest assistance from the study therapist as well as help from their primary caregivers 444 so they could be reminded that these thoughts were creating negative feelings. All nine 
445 patients seemed pleased to receive home-based therapy, and no patient considered it

446 invasive to their family privacy. For 8 out of 9 patients, therapy was delivered to both

447 the patient and the primary caregiver or family member. Therefore, it is probable that

448 caregivers also developed strategies to cope with the disease of their loved one. For

449 example, they practiced relaxation techniques and worked to modify negative thoughts

450 related to the disease and to the way they were living with their loved one's disease.

\section{Discussion}

\section{Interpreting and Integrating the Current Findings}

In this research, data showed that the intervention had moderate positive effects

in both depression and anxiety scores. The standardized mean differences (SMD)

obtained were pretty similar to those reported in a recent meta-analysis of

psychotherapy for depression (current research: -0.76 ; meta-analysis: -0.67 ) and

anxiety (current research: -0.54 ; meta-analysis: -0.65 as secondary outcome) among

advanced and incurable cancer patients (Okuyama et al., 2017). These similarities are

remarkable given the differences in research designs and participant characteristics in

each study. The present research was focused on terminally ill cancer patients very

461 close to their death while most of the international research was focused on advanced

462 cancer patients with a better middle-term prognosis, functionality and medical system

463 context than those in Mexico (Edelman et al., 1999; Greer et al., 2012; Lévesque et al.,

464 2004; Moorey et al., 2009; Savard et al., 2006).

This tailored CBT approach increased leisure behaviors in patients. Increased self-reported behavioral activities are an important indicator of decreased depression

467 (Dobson \& Dobson, 2009). It has also been reported that regardless of the deterioration 
of the cancer patient, activities can be adapted so patients can carry them out in their everyday lives, and this becomes an aid for a better emotional state (Greer et al., 2010; Moorey \& Greer, 2012). Similarly, changes in negative thoughts were observed.

471 Alternative thoughts that helped patients to feel calmer despite disease progression were

472 developed. Similar data have been reported in previous empirical studies where

473 modifying negative ideas became central to the emotional wellbeing of the advanced 474 cancer patient (Lévesque et al., 2004; Savard et al., 2006). Also, the classification of negative thoughts described in the results of this paper could be helpful to further understand and screen types of negative thoughts and their triggers in terminal cancer patients in Mexico, and likely present in other developing countries. Additionally, it might be useful to consider the portion describing that many patients with low schooling

479 levels had difficulties understanding some components of the therapy; particularly, those related to cognitive restructuring. On this point, the international literature has reported that a low schooling level is a distinctive condition of the Latin American population. The recommendation is to identify and adapt the therapy components to the cultural and educational situation of this population. Some suggestions are the use of proverbs, consideration of participants' sociocultural environment when working on behavioral activation, and incorporation of cultural values (Ramos \& Alegría, 2014). caregivers. These results were corroborated through the reports of caregivers who 488 perceived CBT to be positive and useful. It seems possible that this intervention led to important outcomes for patients with a very high disease burden. Caregivers could participate in the therapy together with the patient, which empowered caregivers to help

491 patients to remember and apply the content delivered during each therapy session. The 492 family structure and care given to patients could become an important factor to consider 
493 for future research in terminal cancer patients (Ferrell et al., 2017), as well as protective

494 or supportive factors that make patients value having good social support networks. In

495 addition, the cultural adaptations of this therapy were helpful in ensuring that patients

496 did not stop therapy due to problems related to physical symptoms, transportation, or

497 lack of financial resources. Finally, using SCED in this population seems a viable

498 option to produce initial evidence on the effects of psychological intervention in

499 terminal cancer patients. It also seems to be an option to prevent terminal cancer

500 patients from being subjected to a long wait in control groups or while new intervention

501 groups are formed (waiting times can be of up to ten months; Edelman et al., 1999). The

502 SCED can prevent an increase in their physical deterioration or death before they

503 receive any therapeutic support.

\section{Limitations and Future Research}

Regarding the limitations of the data obtained in this research, it should be noted

506 that this study faced many clinical and methodological challenges during its

507 implementation. It is worrisome that only $9(8 \%)$ out of 117 potential patients assessed

508 at the Palliative Care Department were healthy enough (i.e., could talk, pay attention,

509 and follow instructions) to receive psychological help. Anecdotally, most patients

510 passed away shortly after their first medical palliative assessment. This is a significant

511 problem for the healthcare system in Mexico, which fails to provide adequate and

512 timely cancer screening. Moreover, delayed medical referrals to palliative care and

513 failure to seek medical help have been associated with the high rate of deterioration of

514 cancer patients in Latin America and Mexico (Goss et al., 2013; Torres-Vigil, Aday, De

515 Lima \& Cleeland, 2007). Additionally, some patients experienced distressing symptoms

516 during therapy, such as pain, vomiting, fatigue. Due to these symptoms, at times 
517 therapists had to interrupt the session for some minutes to help the patient to feel better.

518 Understandably, the clinical application of therapy in this population is very

519 challenging. To the extent possible, the Risk of Bias in N-of-1 Trials (RoBiNT) criteria were

521 followed to promote the internal and external validity of this study (Tate et al., 2013);

522 however, caution must be taken when generalizing the data in this research, particularly

523 in what pertains the following: when using a SCED it is advisable to have at least three

524 to five data points per phase in order to analyze single-subject data (Kratochwill et al.,

525 2010). This study was unable to collect at least five data points per phase because

526 patients' physical symptoms or deaths made it impossible to continue to collect such

527 records. Even though having a short baseline worked well for clinical and ethical

528 purposes, this decision might have prevented the criteria from achieving a more

529 complete and exhaustive analysis of the data collected. Also, given the nature of this

530 research, it was not possible to keep participants, investigators, and assessors unaware

531 of the intervention goals; therefore, blinding was not achieved.

Many problems were faced in getting patients or their caregivers to complete

their behavior records. Missing records is a common issue among Mexican patients, and

534 the international literature has reported the same problem in the field (Lévesque et al.,

535 2004). The behaviors that could be recorded were only included in the report filled out

536 by the patient and their relative. Although terminal cancer literature has proved this to

537 be a common and useful approach to avoid assigning more complex tasks to the patient

538 and their relative, current literature in general contexts has suggested that these methods

539 are not sophisticated enough. Therefore, there is an ongoing need for more reliable

540 measuring methods that lay out how to codify and analyze these behaviors (Busch et al., 
541 2010). Another consideration is that patients could have reported what they believed

542 researchers wanted to hear. Social desirability bias is a serious problem in research

543 involving self-report measurements, which can be true in behavioral and thoughts

544 records. Nevertheless, self-reporting tools seem to provide the most feasible

545 measurements for depression and anxiety in advanced cancer patients. To help avoid

546 this potential bias, independent researchers completed the assessments with the patients

547 and their relatives, explaining the importance of being honest and descriptive in their

548 reports. However, we did not measure whether this action had an effect on the accuracy

549 of the information provided by the patients and their relatives. A final consideration is

550 that we did not use a diagnostic interview to determine diagnoses of depressive or

551 anxiety disorders per a formal classification system. Yet, the literature has amply

552 reported the complexity of assessing the varied range of these disorders in the advanced

553 cancer population. The latter relates to the impossibility_of identifying whether the

554 physical symptoms reported were due to anxiety or depression, the development of

555 cancer, or as a side effect of the treatment (Okuyama et al., 2017). Given the design

556 selected for this study and the limitations described above, the resulting data should be

557 taken as an initial approach to the effects of intervention. Further studies that may

558 confirm these findings are recommended.

\section{Implications of the Findings}

560 It seems that a tailored CBT intervention might be a successful clinical

561 approach for terminal cancer patients with depression and anxiety symptoms in the

562 Mexican context. Nevertheless, this therapy (or any psychological therapy) is not an

563 option for patients without sufficient performance status to participate in therapy. Sadly,

564 as described before, most of the Mexican terminal cancer patients are in this situation. It 
565 is our hope that these findings help to encourage the Mexican Healthcare System to

566 overcome this barrier in order to provide better supportive care for this population.

567 Future institutional steps should develop campaigns aimed at identifying cancer at

568 earlier stages (Goss et al., 2013), as well as raising awareness on the benefits of

569 integrating palliative care early in the course of care for patients with metastatic cancer.

570 Research has indeed shown that in doing so, patients' quality of life, emotional distress,

571 and wellbeing will benefit (Ferrell et al., 2017; Temel et al., 2010). Finally, we can

572 conclude that brief, tailored home-based CBT might be a clinically valid option as an

573 aid to address anxiety and depression symptoms in Mexican patients with terminal

574 cancer who are close to their death.

575

\section{References}

57Anderson, T., Watson, M., \& Davidson, R. (2008). The use of cognitive behavioural therapy

577 techniques for anxiety and depression in hospice patients: A feasibility study. Palliative

578 Medicine, 22(7), 814-821. http://doi.org/10.1177/0269216308095157

579ustin, P., Wiley, S., McEvoy, P. M., \& Archer, L. (2011). Depression and anxiety in

580 palliative care inpatients compared with those receiving palliative care at home.

581 Palliative \& Supportive Care, 9(4), 393-400.

582 https://doi.org/10.1017/S1478951511000411

58Barallat, E., Nabal, M., Canal, J., Trujillano, J., Gea-Sánchez, M., Larkin, P. J., \& Downing,

584 M. G. (2017). The Spanish Adaptation of the Palliative Performance Scale (Version 2)

585 Among Cancer Patients at the End of Life: Psychometric Properties. Journal of Pain

586 and Symptom Management, 54(4), 570-577.e5.

587 https://doi.org/10.1016/j.jpainsymman.2017.07.014 
58Bernal, G., Bonilla, J., \& Bellido, C. (1995). Ecological validity and cultural sensitivity for 589 outcome research: Issues for the cultural adaptation and development of psychosocial 590 treatments with Hispanics. Journal of Abnormal Child Psychology, 23(1), 67-82.

59Bjelland, I., Dahl, A. A., Haug, T. T., \& Neckelmann, D. (2002). The validity of the Hospital 592 Anxiety and Depression Scale. An updated literature review. Journal of Psychosomatic 593 Research, 52(2), 69-77.

59ß3usch, A. M., Uebelacker, L. A., Kalibatseva, Z., \& Miller, I. W. (2010). Measuring 595 homework completion in behavioral activation. Behavior Modification, 34(4), 310-329. 596 https://doi.org/10.1177/0145445510373384

59Carvajal, A., Hribernik, N., Duarte, E., Sanz-Rubiales, A., \& Centeno, C. (2013). The 598 Spanish version of the Edmonton Symptom Assessment System-revised (ESAS-r): first 599 psychometric analysis involving patients with advanced cancer. Journal of Pain and 600 Symptom Management, 45(1), 129-136.

601 https://doi.org/10.1016/j.jpainsymman.2012.01.014

60Cohen, J. (1992). A power primer. Psychological Bulletin, 112(1), 155-159.

606onsejo Nacional de Evaluación de la Política de Desarrollo Social (2015). CONEVAL 604 informa los resultados de la medición de pobreza 2014. Retrieved from 605 http://www.coneval.org.mx/SalaPrensa/Documents/Comunicado005_Medicion_pobreza 606 _2014.pdf

60Covarrubias-Gómez, A., Hernández-Martínez, E. E., Ruiz-Ramírez, S., \& López Collada608 Estrada, M. (2014). Assessment of pain and other symptoms in Mexican patients with 609 advanced illness. Journal of Pain \& Palliative Care Pharmacotherapy, 28(4), 394-398. 610 http://doi.org/10.3109/15360288.2014.959235 
61De Vos, S., Solís, P., \& Montes de Oca, V. (2004). Receipt of assistance and extended family

612 residence among elderly men in Mexico. International Journal of Aging \& Human

613 Development, 58(1), 1-27.

61円elgado-Guay, M., Parsons, H. A., Li, Z., Palmer, J. L., \& Bruera, E. (2009). Symptom

615 distress in advanced cancer patients with anxiety and depression in the palliative care

616 setting. Supportive Care in Cancer, 17(5), 573-579. http://doi.org/10.1007/s00520-008-

$617 \quad 0529-7$

61Bobson, D., y Dobson, K. (2009). Evidence-based practice of cognitive behavioral therapy.

619 New York, NY: Guilford Publications

62Edelman, S., Bell, D. R., \& Kidman, A. D. (1999). A group cognitive behaviour therapy 621 programme with metastatic breast cancer patients. Psycho-Oncology, 8(4), 295-305.

622 http://doi.org/10.1002/(SICI)1099-1611(199907/08)8:4<295::AID-PON386>3.0.CO;2$623 \mathrm{Y}$

62Æerrell, B. R., Temel, J. S., Temin, S., Alesi, E. R., Balboni, T. A., Basch, E. M., ... Smith, 625 T. J. (2017). Integration of Palliative Care Into Standard Oncology Care: American 626 Society of Clinical Oncology Clinical Practice Guideline Update. Journal of Clinical

627 Oncology: Official Journal of the American Society of Clinical Oncology, 35(1), 96-

628 112. https://doi.org/10.1200/JCO.2016.70.1474

62Graham, J. E., Karmarkar, A. M., \& Ottenbacher, K. J. (2012). Small sample research 630 designs for evidence-based rehabilitation: Issues and Methods. Archives of Physical 631 Medicine and Rehabilitation, $\quad$ 93(S2), $111-\mathrm{S} 116$. 632 https://doi.org/10.1016/j.apmr.2011.12.017

63Greer. J. A., Graham. J .S., \& Safren, S. A. (2009). Resolving treatment complications 634 associated with comorbid medical conditions. In M. Otto, \& S. Hofmann (Eds.),. 635 Avoiding treatment failure in anxiety disorders (pp. 317-346). New York: Springer. 
636reer, J. A., Park, E. R., Prigerson, H. G., \& Safren, S. A. (2010). Tailoring cognitive637 behavioral therapy to treat anxiety comorbid with advanced cancer. Journal of 638 Cognitive Psychotherapy, 24(4), 294-313. http://doi.org/10.1891/0889-8391.24.4.294

63もreer, J. A., Traeger, L., Bemis, H., Solis, J., Hendriksen, E. S., Park, E. R., ... Safren, S. A. 640 (2012). A pilot randomized controlled trial of brief cognitive-behavioral therapy for 641 anxiety in patients with terminal cancer. The Oncologist, 17(10), 1337-1345. 642 http://doi.org/10.1634/theoncologist.2012-0041

646rissom, R. J. (1994). Probability of the superior outcome of one treatment over another. 644 Journal of Applied Psychology, 79(2), 314-316. http://dx.doi.org/10.1037/0021$645 \quad \underline{9010.79 .2 .314}$

646ross, P. E., Lee, B. L., Badovinac-Crnjevic, T., Strasser-Weippl, K., Chavarri-Guerra, Y., St 647 Louis, J., ... Azenha, G. (2013). Planning cancer control in Latin America and the 648 Caribbean. The Lancet. Oncology, 14(5), 391-436. http://doi.org/10.1016/S1470$649 \quad 2045(13) 70048-2$

650raham, J. E., Karmarkar, A. M., \& Ottenbacher, K. J. (2012). Small sample research 651 designs for evidence-based rehabilitation: Issues and Methods. Archives of Physical 652 Medicine and Rehabilitation, 93(S2), S111-S116. 653 https://doi.org/10.1016/j.apmr.2011.12.017

65łannon, B., Dyck, M., Pope, A., Swami, N., Banerjee, S., Mak, E., ... Zimmermann, C. 655 (2015). Modified Edmonton Symptom Assessment System including constipation and 656 sleep: validation in outpatients with cancer. Journal of Pain and Symptom Management, 657 49(5), 945-952. http://doi.org/10.1016/j.jpainsymman.2014.10.013

65\$ledges, L. V., Pustejovsky, J. E., \& Shadish, W. R. (2013). A standardized mean difference 659 effect size for multiple baseline designs across individuals. Research Synthesis 660 Methods, 4(4), 324-341. https://doi.org/10.1002/jrsm.1086 Ci 
66Hinz, A., Finck, C., Gómez, Y., Daig, I., Glaesmer, H., \& Singer, S. (2014). Anxiety and 662 depression in the general population in Colombia: Reference values of the Hospital 663 Anxiety and Depression Scale (HADS). Social Psychiatry and Psychiatric 664 Epidemiology, 49(1), 41-49. https://doi.org/10.1007/s00127-013-0714-y

66ظlotopf, M., Chidgey, J., Addington-Hall, J., \& Ly, K. L. (2002). Depression in advanced 666 disease: a systematic review Part 1. Prevalence and case finding. Palliative Medicine, $667 \quad 16(2), 81-97$.

66\$acobson, N. S., \& Truax, P. (1991). Clinical significance: a statistical approach to defining 669 meaningful change in psychotherapy research. Journal of Consulting and Clinical 670 Psychology, 59(1), 12-19.

671

67Penson, W. R., Clark, E., Kircher, J. C., \& Kristjansson, S. D. (2007). Statistical reform: 673 Evidence-based practice, meta-analyses, and single subject designs. Psychology in the 674 Schools, 44(5), 483-493. https://doi.org/10.1002/pits.20240

67Kazdin, A. E. (2011). Single-case research designs: Methods for clinical and applied 676 settings (2nd ed.). New York, NY: Oxford University Press.

67Kratochwill, T. R., Hitchcock, J., Horner, R. H., Levin, J. R., Odom, S. L., Rindskopf, D. M., 678 \& Shadish, W. R. (2010). Single-case designs technical documentation. What Works 679 Clearing- house website:http://ies.ed.gov/ncee/wwc/pdf/wwc_scd.pdf 68Dau, F., Downing, M., Lesperance, M., Karlson, N., Kuziemsky, C., \& Yang, J. (2009). 681 Using the Palliative Performance Scale to provide meaningful survival estimates. 682 Journal of Pain and Symptom Management, 38(1), 134-144.

683 http://doi.org/10.1016/j.jpainsymman.2008.05.017 
68\#edford, J. R., Lane, J. D., \& Severini, K. E. (2018). Systematic use of visual analysis for 685 assessing outcomes in single case design studies. Brain Impairment, 19(1), 4-17.

686 https://doi.org/10.1017/BrImp.2017.16

68Zévesque, M., Savard, J., Simard, S., Gauthier, J. G., \& Ivers, H. (2004). Efficacy of 688 cognitive therapy for depression among women with metastatic cancer: A single-case 689 experimental study. Journal of Behavior Therapy and Experimental Psychiatry, 35(4), 690 287-305. http://doi.org/10.1016/j.jbtep.2004.05.002

69lobo, M. A., Moeyaert, M., Cunha, A. B., \& Babik, I. (2017). Single-case design, analysis, 692 and quality assessment for intervention research. Journal of Neurologic Physical 693 Therapy, 41(3), 187-197. https://doi.org/ 10.1097/NPT.0000000000000187

69łobo, A., Saz, P., Marcos, G., Día, J. L., de la Cámara, C., Ventura, T., ... Aznar, S. (1999). 695 Revalidación y normalización del Mini-Examen Cognoscitivo (primera versión en 696 castellano del Mini-Mental Status Examination) en la población general geriátrica[Re697 validation of the Mini-Examen Cognoscitivo (first Spanish version of the Mini-Mental 698 Status Examination) in elderly people]. Medicina Clínica, 112(20), 767-774.

699ópez-Alvarenga, J. C., Vázquez-Velázquez, V., Arcila-Martínez, D., Sierra-Ovando, A. E., 700 González-Barranco, J., \& Salín-Pascual, R. J. (2002). Exactitud y utilidad diagnóstica 701 del hospital anxiety and Depression Scale (HAD) en una muestra de sujetos obsesos 702 mexicanos [Accuracy and diagnostic utility of the Hospital Anxiety and Depression 703 Scale (HAD) in a sample of obese Mexican patients]. Revista de Investigación Clínica, $70454(5), 403-409$.

70\$anolov, R. (2018). Linear Trend in Single-Case Visual and Quantitative Analyses.

706 Behavior Modification, 145445517726301. https://doi.org/10.1177/0145445517726301

707 https://manolov.shinyapps.io/Overlap/ 
708itchell, A. J., Chan, M., Bhatti, H., Halton, M., Grassi, L., Johansen, C., \& Meader, N.

709 (2011). Prevalence of depression, anxiety, and adjustment disorder in oncological,

710 haematological, and palliative-care settings: A meta-analysis of 94 interview-based

711 studies. The Lancet. Oncology, 12(2), 160-174. http://doi.org/10.1016/S1470-

$712 \quad 2045(11) 70002-X$

71Mitchell, A. J., Meader, N., \& Symonds, P. (2010). Diagnostic validity of the Hospital

714 Anxiety and Depression Scale (HADS) in cancer and palliative settings: A meta-

715 analysis. Journal of Affective Disorders, 126(3), 335-348.

716 http://doi.org/10.1016/j.jad.2010.01.067

71Moorey, S., Cort, E., Kapari, M., Monroe, B., Hansford, P., Mannix, K., ... Hotopf, M.

718 (2009). A cluster randomized controlled trial of cognitive behaviour therapy for

719 common mental disorders in patients with advanced cancer. Psychological Medicine,

720 39(5), 713-723. http://doi.org/10.1017/S0033291708004169

72Moorey, S., \& Greer, S. (2012). Cognitive behaviour therapy for people with cancer (2nd 722 ed.). Oxford, UK: Oxford University Press.

72Borley, S., Dowzer, C.N. (2014). Manual for the Leeds Reliable Change Indicator: Simple

724 Excel(tm) applications for the analysis of individual patient and group data. University

725 of Leeds, Leeds, UK.

72Jorcross, J. C. (2011). Psychotherapy Relationships that work: Evidence-based

727 responsiveness. Oxford, UK: Oxford University Press.

728ormand, M. P. (2016). Less is more: Psychologists can learn more by studying fewer

729 people. Frontiers in Psychology, 7, e934. https://doi.org/ 10.3389/fpsyg.2016.00934

730kuyama, T., Akechi, T., Mackenzie, L., \& Furukawa, T. A. (2017). Psychotherapy for

731 depression among advanced, incurable cancer patients: A systematic review and meta- 
732 analysis. Cancer Treatment Reviews, 56, 16-27.

733 https://doi.org/10.1016/j.ctrv.2017.03.012

73æadesky, C. A., \& Mooney, K. A. (1990). Presenting the cognitive model to 735 clients. International Cognitive Therapy Newsletter, 6, 13-14

73Barker, R. I., \& Vannest, K. (2009). An improved effect size for single-case research:

737 nonoverlap of all pairs. Behavior Therapy, 40(4), 357-367.

738 http://doi.org/10.1016/j.beth.2008.10.006

739arker, R. I., Vannest, K. J., \& Davis, J. L. (2011). Effect size in single-case research: A

740 review of nine nonoverlap techniques. Behavior Modification, 35(4), 303-322.

$741 \quad$ https://doi.org/10.1177/0145445511399147

74Parker, R. I., Vannest, K. J., Davis, J. L., \& Sauber, S. B. (2011). Combining nonoverlap and

743 trend for single-case research: Tau-U. Behavior Therapy, 42(2), 284-299.

744 https://doi.org/10.1016/j.beth.2010.08.006

74Benrod, J. D., \& Morrison, R. S. (2004). Challenges for palliative care research. Journal of

746 Palliative Medicine, 7(3), 398-402. https://doi.org/10.1089/1096621041349392

74Punja, S., Schmid, C. H., Hartling, L., Urichuk, L., Nikles, C. J., \& Vohra, S. (2016). To

748 meta-analyze or not to meta-analyze? A combined meta-analysis of N-of-1 trial data

749 with RCT data on amphetamines and methylphenidate for pediatric ADHD. Journal of

750 Clinical Epidemiology, 76, 76-81. https://doi.org/10.1016/j.jclinepi.2016.03.021

75Pustejovsky, J. (2016a). scdhlm: A web-based calculator for between-case standardized

752 mean differences (Version 0.3.1) [Web application]. Retrieved from:

753 https://jepusto.shinyapps.io/scdhlm

75¥ustejovsky, J. (2016b). scdhlm: Estimating Hierarchical Linear Models for Single-Case

755 Designs (Version 0.3.1). Retrieved from https://CRAN.R-project.org/package=scdhlm 
75Ramos, Z., \& Alegría, M. (2014). Cultural adaptation and health literacy refinement of a

757 brief depression intervention for Latinos in a low-resource setting. Cultural Diversity \& 758 Ethnic Minority Psychology, 20(2), 293-301. https://doi.org/10.1037/a0035021

75Rayner, L., Price, A., Hotopf, M., \& Higginson, I. J. (2011). The development of evidence-

760 based European guidelines on the management of depression in palliative cancer care.

761 European Journal of Cancer (Oxford, England: 1990), 47(5), 702-712.

762 http://doi.org/10.1016/j.ejca.2010.11.027

76Savard, J., Simard, S., Giguère, I., Ivers, H., Morin, C. M., Maunsell, E., ... Marceau, D.

764 (2006). Randomized clinical trial on cognitive therapy for depression in women with

765 metastatic breast cancer: psychological and immunological effects. Palliative \&

766 Supportive Care, 4(3), 219-237.

76\$chlosser, R. W. (2009). The role of single-subject experimental designs in evidence-based 768 practice times. (FOCUS: Technical Brief 22). National Center for the Dissemination of 769 Disability Research (NCDDR). Retrieved May 24, 2018 from

770 http://ktdrr.org/ktlibrary/articles_pubs/ncddrwork/focus/focus22/Focus22.pdf

77\$hadish, W. R., Hedges, L. V., Horner, R. H., \& Odom, S. L. (2015). The role of between772 case effect size in conducting, interpreting, and summarizing single-case research 773 (NCER-2015-02). Washington, DC: National Center for Education Research, Institute

774 of Education Sciences, U.S. Department of Education. Retrieved on October 12, 2016

775 from http://ies.ed.gov/ncser/pubs/2015002/.

776nodgrass, M. R., Chung, M. Y., Meadan, H., \& Halle, J. W. (2018). Social validity in 777 single-case research: A systematic literature review of prevalence and application. 778 Research in Developmental Disabilities, 74(1), 160-173.

779 https://doi.org/10.1016/j.ridd.2018.01.007 
788pencer, R., Nilsson, M., Wright, A., Pirl, W., \& Prigerson, H. (2010). Anxiety disorders in

781 advanced cancer patients: correlates and predictors of end-of-life outcomes. Cancer, 782 116(7), 1810-1819. http://doi.org/10.1002/cncr.24954

78Stetter, F., \& Kupper, S. (2002). Autogenic training: a meta-analysis of clinical outcome 784 studies. Applied Psychophysiology and Biofeedback, 27(1), 45-98.

$78 \$$ ate, R. L., Perdices, M., Rosenkoetter, U., Shadish, W., Vohra, S., Barlow, D. H., ...

786 Wilson, B. (2016). The Single-Case Reporting Guideline In Behavioral Interventions

787 (SCRIBE) 2016 Statement. Archives of Scientific Psychology, 4, 10-31.

788 https://doi.org/10.1080/09602011.2016.1190533

789ate, R. L., Perdices, M., Rosenkoetter, U., Wakim, D., Godbee, K., Togher, L., \&

790 McDonald, S. (2013). Revision of a method quality rating scale for single-case

791 experimental designs and n-of-1 trials: the 15-item Risk of Bias in N-of-1 Trials

792 (RoBiNT) Scale. Neuropsychological Rehabilitation, 23(5), 619-638.

793 https://doi.org/10.1080/09602011.2013.824383

794emel, J. S., Greer, J. A., Muzikansky, A., Gallagher, E. R., Admane, S., Jackson, V. A., ...

795 Lynch, T. J. (2010). Early palliative care for patients with metastatic non-small-cell

796 lung cancer. The New England Journal of Medicine, 363(8), 733-742.

797 https://doi.org/10.1056/NEJMoa1000678

798eunissen, S. C. C. M., Wesker, W., Kruitwagen, C., de Haes, H. C. J. M., Voest, E. E., \& de

799 Graeff, A. (2007). Symptom prevalence in patients with incurable cancer: a systematic 800 review. Journal of Pain and Symptom Management, 34(1), 94-104. 801 http://doi.org/10.1016/j.jpainsymman.2006.10.015

80Torres-Vigil, I., Aday, LA., De Lima, L. \& Cleeland, C.S. (2007). What predicts the quality 803 of advanced cancer care in latin america? a look at five countries: Argentina, Brazil, 
804 Cuba, Mexico, and Peru. Journal of Pain and Symptom Management, 34(3), 315-328.

805 doi.org/10.1016/j.jpainsymman.2006.11.015

806raeger, L., Greer, J. A., Fernandez-Robles, C., Temel, J. S., \& Pirl, W. F. (2012). Evidence-

807 based treatment of anxiety in patients with cancer. Journal of Clinical Oncology,

808 30(11), 1197-1205. http://doi.org/10.1200/JCO.2011.39.5632

80\$annest, K. J., \& Ninci, J. (2015). Evaluating intervention effects in single-case research

810 designs. Journal of Counseling \& Development, 93(4), 403-411.

811 http://dx.doi.org/10.1002/jcad.12092

81Уannest, K.J., Parker, R.I., Gonen, O., \& Adiguzel, T. (2016). Single Case Research: web

813 based calculators for SCR analysis. (Version 2.0) [Web-based application]. College

814 Station, TX: Texas A\&M University. Retrieved Tuesday 24th April 2018. Available

815 from singlecaseresearch.org

81\$odermaier, A., Linden, W., \& Siu, C. (2009). Screening for emotional distress in cancer

817 patients: A systematic review of assessment instruments. Journal of the National

818 Cancer Institute, 101(21), 1464-1488. http://doi.org/10.1093/jnci/djp336

81\$ei, L. A., Fearing, M. A., Sternberg, E. J., \& Inouye, S. K. (2008). The Confusion

820 Assessment Method: A systematic review of current usage. Journal of the American

821 Geriatrics Society, 56(5), 823-830. http://doi.org/10.1111/j.1532-5415.2008.01674.x

82Zigmond, A. S., \& Snaith, R. P. (1983). The hospital anxiety and depression scale. Acta

823 Psychiatrica Scandinavica, 67(6), 361-370.

824 
Cohort 1
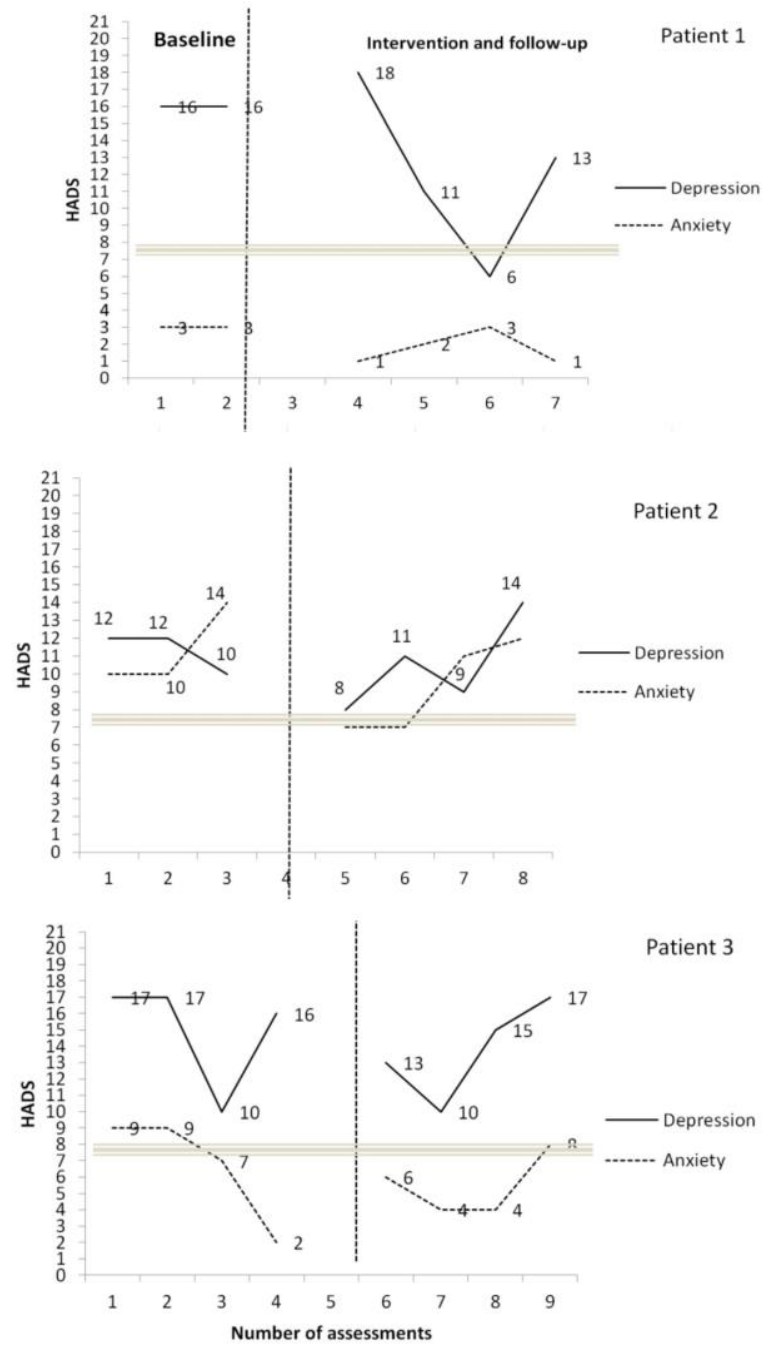

Cohort 2

Cohort 3
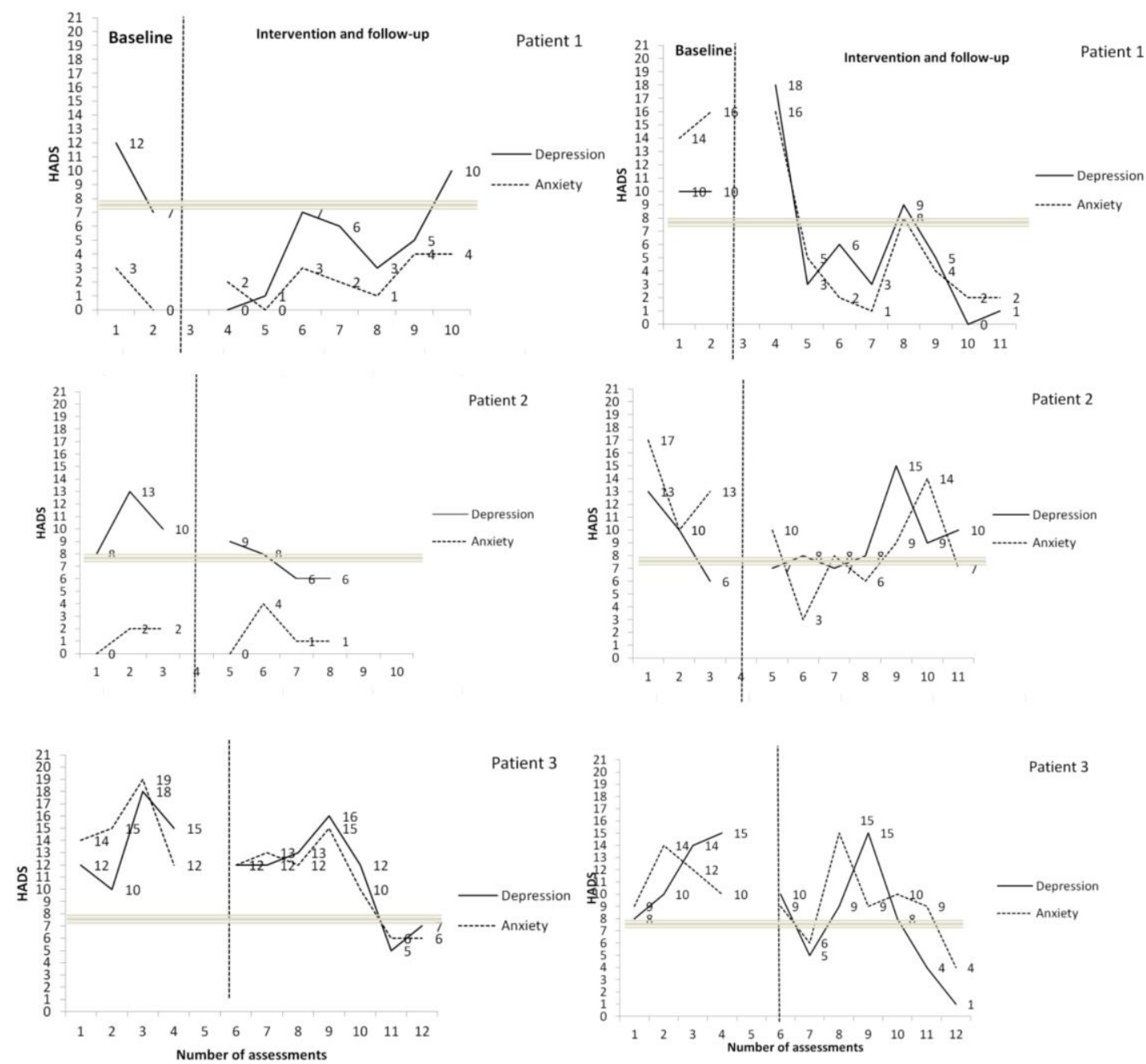

Figure 1. HADS score of depression and anxiety symptoms for the nine participants from the three cohorts 
Table 1. Demographic characteristics of each patient

\begin{tabular}{|c|c|c|c|c|c|c|c|c|}
\hline Participant & Age & Sex & Edu. & Functionality & Cancer diagnosis & $\begin{array}{c}\text { Mood } \\
\text { problem }\end{array}$ & $\begin{array}{l}\text { Medica } \\
\text { tion* }\end{array}$ & $\begin{array}{c}\text { Life } \\
\text { span+ }\end{array}$ \\
\hline $\begin{array}{l}\text { Patient 1, Cohort } \\
1\end{array}$ & 81 & $\mathrm{~F}$ & IES & $\begin{array}{l}\text { Mostly in bed } \\
(\mathrm{PPS}=40)\end{array}$ & $\begin{array}{l}\text { Kidney cancer/lung and } \\
\text { liver metastases }\end{array}$ & Depression & None & 88 days \\
\hline $\begin{array}{l}\text { Patient 2, Cohort } \\
1\end{array}$ & 49 & $\mathrm{~F}$ & IES & $\begin{array}{l}\text { Slow and limited } \\
\text { ambulation } \\
(\mathrm{PPS}=60)\end{array}$ & $\begin{array}{l}\text { Cervical cancer/stomach } \\
\text { metastasis }\end{array}$ & $\begin{array}{l}\text { Depression } \\
\text { \& anxiety }\end{array}$ & None & 64 days \\
\hline $\begin{array}{l}\text { Patient 3, Cohort } \\
1\end{array}$ & 69 & M & IES & $\begin{array}{l}\text { Slow and limited } \\
\text { ambulation } \\
(\mathrm{PPS}=60)\end{array}$ & $\begin{array}{l}\text { Colon cancer/liver } \\
\text { metastases }\end{array}$ & $\begin{array}{l}\text { Depression } \\
\text { \& anxiety }\end{array}$ & None & 79 days \\
\hline $\begin{array}{l}\text { Patient 1, Cohort } \\
2\end{array}$ & 44 & M & HS & $\begin{array}{l}\text { No evidence of } \\
\text { disease }(P P S=90)\end{array}$ & $\begin{array}{l}\text { Pancreatic cancer/liver } \\
\text { metastases }\end{array}$ & $\begin{array}{l}\text { Depression } \\
\text { \& anxiety }\end{array}$ & $\begin{array}{l}\text { Fluoxet } \\
\text { ine** }\end{array}$ & $\begin{array}{l}302 \\
\text { days }\end{array}$ \\
\hline $\begin{array}{l}\text { Patient 2, Cohort } \\
2\end{array}$ & 65 & $\mathrm{~F}$ & IES & $\begin{array}{l}\text { Normal activity } \\
\text { with effort } \\
(P P S=80)\end{array}$ & $\begin{array}{l}\text { Pancreatic cancer/thyroid } \\
\text { metastasis }\end{array}$ & Depression & None & 64 days \\
\hline $\begin{array}{l}\text { Patient 3, Cohort } \\
2\end{array}$ & 83 & $\mathrm{~F}$ & $\mathrm{TC}$ & $\begin{array}{l}\text { Mainly on couch } \\
\text { and bed (PPS }=50)\end{array}$ & $\begin{array}{l}\text { Cervical cancer/bone } \\
\text { metastases }\end{array}$ & Depression & None & $\begin{array}{l}493 \\
\text { days }\end{array}$ \\
\hline $\begin{array}{l}\text { Patient 1, Cohort } \\
3\end{array}$ & 63 & M & ES & $\begin{array}{l}\text { Inability to } \\
\text { perform activities } \\
\text { at home (PPS }=70 \text { ) }\end{array}$ & $\begin{array}{l}\text { Liver cancer/stomach } \\
\text { metastasis }\end{array}$ & $\begin{array}{l}\text { Depression } \\
\text { \& anxiety }\end{array}$ & None & $\begin{array}{l}160 \\
\text { days }\end{array}$ \\
\hline $\begin{array}{l}\text { Patient 2, Cohort } \\
3\end{array}$ & 76 & $\mathrm{M}$ & ES & $\begin{array}{l}\text { Normal activity } \\
\text { with effort } \\
(P P S=80)\end{array}$ & $\begin{array}{l}\text { Liver cancer/stomach } \\
\text { metastasis }\end{array}$ & $\begin{array}{l}\text { Depression } \\
\text { \& anxiety }\end{array}$ & $\begin{array}{l}\text { Fluoxet } \\
\text { ine }^{* *}\end{array}$ & 89 days \\
\hline $\begin{array}{l}\text { Patient 3, Cohort } \\
3\end{array}$ & 40 & $\mathrm{~F}$ & $\mathrm{TC}$ & $\begin{array}{l}\text { Mainly on chair } \\
\text { and bed (PPS=50) }\end{array}$ & $\begin{array}{l}\text { Ovarian cancer/uterus } \\
\text { metastasis }\end{array}$ & $\begin{array}{l}\text { Depression } \\
\text { \& anxiety }\end{array}$ & None & $\begin{array}{l}\text { Informat } \\
\text { ion not } \\
\text { availabl } \\
\text { e }\end{array}$ \\
\hline
\end{tabular}

Note: F=Female; M= Male; Edu.=Education; IES=Incomplete elementary school; ES=Elementary school; HS=High School; TC=Technical career; PPS=Palliative Performance Scale; *= Psychotropic Medication; **=20 milligrams per day; +=From the first assessment at the Palliative Care Department until the day they died. 
Table 2. Cultural adaptation of CBT in the context of advanced cancer in Mexico

\begin{tabular}{ll}
\hline \multicolumn{1}{c}{$\begin{array}{c}\text { Mexican Cultural } \\
\text { elements }\end{array}$} & \multicolumn{1}{c}{ Resulting adaptation } \\
\hline $\begin{array}{l}\text { Short life expectancy } \\
\text { Distressing physical } \\
\text { symptoms }\end{array}$ & $\begin{array}{l}\text { Brief therapy (4-6 sessions) in three weeks } \\
\text { Psychological techniques for anxiety and physical symptoms }\end{array}$ \\
& $\begin{array}{l}\text { Home-based therapy reducing the burden of travel on patients and } \\
\text { families who may be unable to visit the hospital due to illness and } \\
\text { symptoms } \\
\text { Home-based therapy reducing the burden of travel on patients and } \\
\text { families who may be unable to visit the hospital due to lack of } \\
\text { financial resources. Treatment protocol was adapted to } \\
\text { socioeconomic and psychosocial contextual issues }\end{array}$ \\
$\begin{array}{l}\text { Poverty } \\
\text { Simple examples of CBT components were used. Examples of patient's } \\
\text { daily life events were used } \\
\text { education } \\
\begin{array}{l}\text { Extended family } \\
\text { structure }\end{array}\end{array}$ \\
$\begin{array}{l}\text { Flexibility for integrating extended family into CBT therapy A lot of } \\
\text { sessions in the study were provided on weekends before the meal } \\
\text { time when all the relatives were together }\end{array}$ \\
$\begin{array}{l}\text { Treatment in the study was provided using the cultural meaning of } \\
\text { Mexican-Spanish words. Cultural likes were taken to create better } \\
\text { relationship and understanding of concepts }\end{array}$ \\
\hline
\end{tabular}

Note: CBT= Cognitive Behavioral Therapy 
Table 3. Components of cognitive behavioral therapy manual for anxiety and depression

\begin{tabular}{|c|c|c|}
\hline Module & Objectives & Techniques \\
\hline $\begin{array}{l}\text { I. Psycho- } \\
\text { education on }\end{array}$ & $\begin{array}{l}\text { Create a good therapy relationship } \\
\text { between patient and therapist }\end{array}$ & $\begin{array}{l}\text { Alliance } \\
\text { Empathy } \\
\text { Goal Consensus and collaboration }\end{array}$ \\
\hline CBT principles & $\begin{array}{l}\text { Help patients identify the } \\
\text { relationships among thoughts, } \\
\text { behaviors and feelings }\end{array}$ & Review CBT model within context of patients daily life. \\
\hline $\begin{array}{l}\text { II. Relaxation } \\
\text { training }\end{array}$ & $\begin{array}{l}\text { Teaching patients to use a variety of } \\
\text { relaxation techniques in order to } \\
\text { control anxiety and physical } \\
\text { symptoms }\end{array}$ & $\begin{array}{l}\text { CD or MP3 with directions about: } \\
\text { Autogenic relaxation } \\
\text { Guided imagery } \\
\text { Pursed-lip breathing }\end{array}$ \\
\hline $\begin{array}{l}\text { III. Negative } \\
\text { thoughts related } \\
\text { to anxiety and } \\
\text { depression } \\
\text { IV. Planning } \\
\text { activities and } \\
\text { strategies for } \\
\text { managing } \\
\text { physical } \\
\text { symptoms }\end{array}$ & $\begin{array}{l}\text { Identify and modify negative } \\
\text { thoughts associated with anxiety and } \\
\text { depression in terminal cancer } \\
\text { Identify and engage in leisure } \\
\text { behaviors or activities that patients } \\
\text { could perform according to their } \\
\text { daily physical capacities } \\
\text { Reinforce patients' efforts to focus } \\
\text { their attention on pleasant events to } \\
\text { help tolerate distressing physical } \\
\text { symptoms }\end{array}$ & $\begin{array}{l}\text { Review CBT model of anxiety and depression within context of terminal } \\
\text { cancer } \\
\text { Identify negative thoughts related to the disease } \\
\text { Change negative thoughts with more adaptive and comforting thoughts } \\
\text { Some activities proposed by patients were: } \\
\text { Watching classical Mexican movies; watching soccer matches of the FIFA } \\
\text { World Cup; watching Mexican soap operas; reading books; reading the } \\
\text { bible; listening to religious songs; visiting with family; walking around a } \\
\text { nearby park; sunbathing; helping make a meal; cleaning small objects } \\
\text { around the house; fixing things around the house; singing; telling stories } \\
\text { of their life to their grandchildren; playing with their young children; } \\
\text { weaving; or playing with bird seeds or beads }\end{array}$ \\
\hline
\end{tabular}


Table 4. NAP and Tau-U indices values for depression and anxiety

\begin{tabular}{llll}
\hline Participant & Index & Value & $\begin{array}{l}\text { 90\% Confidence } \\
\text { interval }\end{array}$ \\
\hline & Depression & & \\
Patient 1, Cohort 1 & NAP & -0.75 & -1 to 0.39 \\
Patient 2, Cohort 1 & Tau-U & -0.67 & -1 to 0.11 \\
Patient 3, Cohort 1 & NAP & -0.66 & -1 to 0.40 \\
Patient 1, Cohort 2 & Tau-U & -0.71 & -1 to 0.09 \\
Patient 2, Cohort 2 & NAP & -0.88 & -1 to 0.03 \\
Patient 3, Cohort 2 & NAP & -0.60 & -0.85 to 0.44 \\
Patient 1, Cohort 3 & NAP & -0.88 & -1 to 0.04 \\
Patient 2, Cohort 3 & Tau-U & 0.05 & -0.64 to 0.74 \\
Patient 3, Cohort 3 & NAP & -0.81 & -1 to -0.02 \\
& Anxiety & & \\
Patient 1, Cohort 1 & NAP & -0.88 & -1 to 0.14 \\
Patient 2, Cohort 1 & NAP & -0.67 & -1 to 0.44 \\
Patient 3, Cohort 1 & Tau-U & -0.06 & -0.78 to 0.65 \\
Patient 1, Cohort 2 & Tau-U & 0.36 & -0.45 to 1 \\
Patient 2, Cohort 2 & NAP & -0.54 & -0.86 to 0.69 \\
Patient 3, Cohort 2 & NAP & -0.84 & -1 to -0.06 \\
Patient 1, Cohort 3 & NAP & -0.91 & -1 to -0.03 \\
Patient 2, Cohort 3 & Tau-U & -0.71 & -1 to -0.03 \\
Patient 3, Cohort 3 & Tau-U & -0.53 & -1 to 0.07 \\
\hline Note: Negativeresult & indicate decrease(ie, & Nor \\
\hline
\end{tabular}

Note: Negative results indicate decrease (i.e., improvement). Note that the standard errors used to construct the confidence intervals of NAP and Tau-U assume independent data. 